\author{
WOLFGANG WÜST \\ Friedrich-Alexander-Universität Erlangen-Nürnberg \\ E-Mail: wolfgang.wuest@fau.de \\ ORCID ID: https://orcid.org/0000-0001-7873-5996
}

\title{
ZUR EUROPÄISCHEN DISKUSSION ÜBER DEN RELIGIONSKRIEG IN DEN JAHREN 1679-1714
}

$\mathrm{Zu}$ Beginn seiner umfangreichen, auf breiter Forschungsliteratur (S. 534-578) resultierenden Abhandlung Die europäische Debatte über den Religionskrieg (1679-1714). Konfessionelle Memoria und internationale Politik im Zeitalter Ludwigs XIV. stellt Christian Mühling die Leitfrage seines Forschungsanliegens, die grundsätzlich in das Feld der national wie international gut untersuchten Konfessions-, Kirchen- und Religionsgeschichte fälltt ${ }^{1}$. Sie lautet: „Ziel der Untersuchung ist es, die Frage zu beantworten, wie sich begriffsgeschichtlich eine Vorstellung, ein Geschichtsbild und ein Epochensignum vom Religionskrieg etablierten“ (S. 13). Der vom Verfasser detailreich belegte zeitliche „Höhepunkt“ der europäischen Diskussion über den Religionskrieg zwischen 1679 und 1714 mag für die französische, savoyardische und evtl. auch die englische Geschichte des 17. und 18. Jahrhunderts zutreffend sein. Für die deutsche Geschichte trifft diese zeitliche Einordnung allerdings nur bedingt $\mathrm{zu}$. Sie blendet sowohl die auf den Reichs- und Kreistagen des 16. Jahrhunderts (insbesondere im Jahr 1555) kontrovers diskutierten Konfessionsfragen als auch den Dreißigjährigen Krieg mit einer bildlich wie schriftlich aggressiv geführten Mediendebatte (Flugblätter) um die kriegsbedingten ,richtigen“ Konfessionsentscheidungen aus. Hier helfen auch die Seitenblicke auf die Türkenkriege und die

${ }^{1}$ Ch. Mühling, Die europäische Debatte über den Religionskrieg (1679-1714). Konfessionelle Memoria und internationale Politik im Zeitalter Ludwigs XIV., (Veröffentlichungen des Instituts für Europäische Geschichte Mainz, Abtl. für Abendländische Religionsgeschichte, Abtl. für Universalgeschichte 250, 2018), 587 S., ISBN 978-3-525-31054-0. 
osmanische Expansion nicht weiter. Sie sprechen zwar grundsätzlich für die späte Datierung der gezeigten Religionskriegsdebatte, spielen aber im vorzustellenden Band aus dem Vandenhoeck \& Ruprecht Verlag keine zentrale Rolle. Aufschlussreicher ist hier dann schon das Kapitel The Glorious Revolution und das Schicksal Jakobs II. von England als Beleg der französischen Argumentation mit dem Religionskrieg (S. 266-276). Diese Revolution wurde in der zeitgenössischen französischen Publizistik als Religionskrieg Wilhelms von Oranien und seiner protestantischen Verbündeten gegen den Katholizismus interpretiert (S. 276).

Kritiker der Religionskriegsführungsdebatte, soweit diese zugespitzt geführt wurde, wie Johannes Burkhardt, werden argumentativ aus dem Weg geräumt mit einem Seitenhieb auf ein essentialistisches Geschichtsverständnis, das - wie bedauerlich - „immer noch von einem Großteil der neueren Forschung geteilt" wird (S. 26). Mühling widerspricht sich hier selbst, wenn er einerseits zu Recht feststellt, dass der religiöse Gehalt an der Kriegsführung und die tatsächlichen Beweggründe der politischen Handlungsträger methodisch nur „sehr schwer“ zu erfassen sind, dass er andererseits ganz zentral die Forschungsthese in Frage stellt, Konfessionsfragen hätten in den internationalen Beziehungen nach 1648 stark an Bedeutung verloren (S. 504).

Worin liegen nun die neuen Erkenntnisse dieser „ersten größeren begriffsgeschichtlichen Untersuchung zu diesem Thema" (S. 503) - wie der Autor keineswegs unbescheiden feststellt - mit Blick auf ein quellenkonformes Fazit europäischer Religionskriegsdebatten? Mit Christian Mühling bleibt festzuhalten, dass 1.) die Propagierung und Verurteilung des Religionskrieges im Zeitalter des französischen „Sonnenkönigs“ Ludwig XIV. kein Signal für einen beginnenden Säkularisationsprozess sei - dieser wurde übrigens von Mediävisten schon für die Zeit der Karolinger reklamiert -, sondern er wäre Ausdruck einer ,zutiefst konfessionell-religiösen Weltsicht" (S. 504). Ferner wurden 2.) die Debatten um den Religionskrieg insbesondere von katholischen und protestantischen Pastoren geführt, wobei die Sicht der Kirchengeschichtsschreibung revidiert werden muss, die Debattenführung sei Sache der Politik und Publizistik gewesen, während Geistliche sich daran kaum beteiligten. 3.) Die Internationalisierung der Religionskriegsdebatte belegt die begriffliche Verdichtung und Wahrnehmung des Religionskrieges um 1700. Problematisch bleibt dabei die zu geringe Bewertung ähnlich gelagerter Debatten aus früherer Zeit. 
Ob das von Mühling angenommene Versiegen des Religionskriegsthemas nach dem Westfälischen Frieden zutrifft, sei dahingestellt. Forschungen zur Predigtliteratur der zweiten Hälfte des 17. Jahrhunderts stehen dazu noch weitgehend aus. 4.) Ein weiteres späteres Feld konfessioneller Auseinandersetzungen im Zeitalter der Kulturkämpfe des 19. Jahrhunderts - es standen sich säkulare und ultramontane Kräfte erbittert gegenüber - wird vom Autor keinesfalls in die Tradition der Religionskriege eingeordnet. Aus kulturhistorischer Perspektive handelt es sich bei den Autoren, die für diese Zeit noch vom Religionskrieg sprechen, allenfalls um ein Missverständnis. Sie gründet auf einer ,vielfach unreflektierten Vermischung von modernem Analyse- und anachronistischem Quellenbegriff und Geschichtsbildern vom Religionskrieg“.

Gut, dass wir jetzt mit Christian Mühling die Debatten um die europäischen Religionskriege genauer datieren und umschreiben können. Ost- und ostmitteleuropäische Konflikte sind dabei leider nicht Teil der Darstellung. Das Europabild ist also westlich zentriert und geprägt; ungedruckte Quellen wurden deshalb mit Ausnahme eines Nachlasses in der Staatsbibliothek Berlin ausschließlich aus den Beständen der französischen Archive, des Ministeriums für Europa und Äußeres (Ministère des Affaires Étrangères) und Archivs des Verteidigungsministeriums und der französischen Armee (Archives Historiques de la Défense) in Paris geschöpft. Die westliche Sicht der Darstellung liegt zu einem weiteren Teil sicher auch in der Tatsache begründet, dass die Forschungsarbeit im November 2016 als deutsch-französische Dissertation an der Université Paris-Sorbonne und der Philipps-Universität Marburg angenommen wurde. Betreut wurde sie von Prof. Dr. Christoph Kampmann (Marburg) und Prof. Dr. Olivier Caline (Paris).

Die Datierungsargumente des Verfassers werden auf Widerspruch stoßen. Das weite Feld der Religionskriege, angefangen von den Kreuzzügen und Albigenser-Kriegen des Mittelalters bis zum Dschihad unserer Tage, der nach der islamischen Rechtslehre den Kampf um die Erweiterung und Verteidigung des Glaubens legitimiert, bis der Islam die beherrschende Religion ist, lässt sich eben nur schwer auf die Zeit um 1700 begrenzen. 
